Jurnal Media Pertanian Vol. 3 No. 2 Tahun 2018 Hal. 54 - 60

Media Komunikasi Hasil Penelitian dan Review Literatur Bidang Ilmu Agronomi ISSN print $2503-1279$ ISSN online $2581-1606$

\title{
KARAKTERISTIK TANAH AREA PASCA PENAMBANGAN DI DESA TANJUNG PAUH
}

\author{
Ida Nursanti \\ Program Studi Agroteknologi, Fakultas Pertanian Universitas Batanghari \\ Jl. Slamet Riyadi-Broni Jambi, 36122. Telp. +62741 60103 \\ Email: ida_unbari@yahoo.co.id
}

\begin{abstract}
The post-mining soil has poor chemical and physical properties and has a very low fertility rate. The objective of this research is to know the land post-mining characteristics related to planting medium. Implementation of research in Tanjung Pauh Village and soil Laboratory. The research was conducted by survey method and soil laboratory test. Data analysis of the diversity of post-mining soil characteristics is presented in table form and discussed descriptively. Post-mine soil chemical and physical characteristic: soil acidity level in very acidic position $\mathrm{pH} 4, \mathrm{Al}$ saturation of high criterion equal to 52,86\%, iron content 1,51\% high

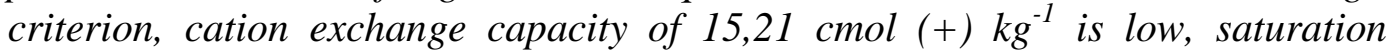
saturation of $49.44 \%$ is moderate, C-organic is very low that is equal to $0.16 \%$, $C / N$ value of soil 1.46 is very low, $N$ total $0,11 \%, P$ available $9,20 \mathrm{mg} \mathrm{kg}^{-1}$ and $K$ total of soil $0,15 \mathrm{mg} \mathrm{kg}^{-1}$ are each classified as low. The post-mining land has poor physical and chemical characteristics of soil as planting medium. Keywords: soil chemistry, physical soil, post mine
\end{abstract}

\begin{abstract}
Abstrak
Tanah pasca penambangan memiliki sifat kimia dan fisik yang kurang baik serta memiliki tingkat kesuburan yang sangat rendah. Penelitian bertujuan mengetahui karakteristik tanah pasca tambang terkait sebagai media tanam. Pelaksanaan penelitian di Desa Tanjung Pauh dan Laboratorium tanah. Penelitian dilaksanakan dengan metode survey dan uji laboratorium tanah. Analisis data keragaman karakteristik jenis tanah pasca penambangan disajikan dalam bentuk tabel dan dibahas secara deskriptif. Karakteristik kimia dan fisik tanah pasca tambang: tingkat kemasaman tanah berada pada posisi sangat masam $\mathrm{pH} 4$, kejenuhan $\mathrm{Al}$ kriteria tinggi sebesar 52,86\%, kadar besi 1,51\% kriteria tinggi, KTK (Kapasitas Tukar Kation) tanah sebesar $15,21 \mathrm{cmol}^{(+) \mathrm{kg}^{-1}}$ tergolong rendah, Kejenuhan Basa (KB) sebesar 49,44\% tergolong sedang, C-organik sangat rendah yaitu sebesar $0,16 \%$, Nilai $\mathrm{C} / \mathrm{N}$ tanah 1,46 tergolong sangat rendah, $\mathrm{N}$ total $0,11 \%, \mathrm{P}$ tersedia $9,20 \mathrm{mg} \mathrm{kg}^{-1}$ dan $\mathrm{K}$ total tanah $0,15 \mathrm{mg} \mathrm{kg}^{-1}$ masing-masing tergolong rendah.Tanah pasca penambangan memiliki karakteristik fisik dan kimia tanah yang kurang baik sebagai media tanam.

Kata kunci : kimia tanah, fisik tanah, pasca tambang
\end{abstract}

Diterbitkan oleh Program Studi Agroteknologi Fakultas Pertanian Universitas Batanghari Jambi Halaman 54 
Jurnal Media Pertanian Vol. 3 No. 2 Tahun 2018 Hal. 54 - 60

Media Komunikasi Hasil Penelitian dan Review Literatur Bidang Ilmu Agronomi ISSN print $2503-1279$ ISSN online $2581-1606$

\section{PENDAHULUAN}

Sumber daya alam merupakan salah satu modal dasar dalam pembangunan Nasional karena itu harus dimanfaatkan untuk kepentingan rakyat dan kepentingan pembangunan nasional dengan memperhatikan kelestariannya. Salah satu kegiatan dalam memanfaatkan sumberdaya alam adalah kegiatan pertambangan bahan galian yang hingga saat ini merupakan salah satu sektor penyumbang devisa negara yang terbesar.

Kegiatan pertambangan apabila tidak dilaksanakan secara tepat dapat menimbulkan dampak negatif terhadap lingkungan terutama gangguan keseimbangan permukaan tanah yang cukup besar. Dampak lingkungan kegiatan pertambangan : penurunan produktivitas tanah, pemadatan tanah, erosi dan sedimentasi, gerakan tanah atau longsor, terganggunya flora dan fauna, terganggunya keamanan dan kesehatan penduduk, serta perubahan iklim mikro (Kailei et al., 2016).

Pertambangan di Provinsi Jambi diantaranya tambang emas, tambang minyak dan tambang batubara. Berdasarkan data yang diperoleh dari Dinas Energi dan Sumber Daya Mineral Provinsi Jambi, luas izin operasi produksi tambang batubara hingga akhir 2015 ini seluas 107.192,1 ha, sedangkan izin eksplorasi mencapai 139.150,1 ha. Proses kegiatan pertambangan batubara diwilayah Provinsi Jambi yang menggunakan teknik penambangan terbuka (open pit mining) dengan metode gali isi kembali (Back fillings method) (Purnamayani, 2016).

Sistem penambangan terbuka yang berada di permukaan tanah banyak mengubah bentang lahan dan keseimbangan ekosistem permukaan tanah. Penambangan timah menurunkan produktivitas tanah dan mutu lingkungan. Struktur tanah penutup rusak, tanah lapisan atas bercampur ataupun terbenam di lapisan dalam. Tanah bagian atas digantikan tanah dari lapisan bawah yang kurang subur, sebaliknya tanah lapisan atas yang subur berada di lapisan bawah. Demikian juga populasi hayati tanah yang ada di tanah lapisan atas menjadi terbenam, sehingga hilang atau mati dan tidak berfungsi sebagaimana mestinya. Daya dukung tanah lapisan atas pasca penambangan untuk pertumbuhan tanaman menjadi rendah (Kodir et al., 2017).

Pada penambangan sistem terbuka nampak bahwa apabila penanganan kurang hati hati permasalahan yang mungkin terjadi adalah perubahan bentang lahan, rusaknya struktur tanah, dan hilangnya tanah lapisan atas. Hasil penelitian Subardja (2009) menunjukkan bahwa lahan bekas penambangan rakyat sistem terbuka memiliki permukaan lahan tidak teratur, kesuburan tanah rendah, dan rawan erosi, sehingga daya dukung tanah untuk tanaman rendah. Lahan terdegradasi umumnya memiliki biota berbeda dengan komunitas ekosistem aslinya, terjadi kecenderungan penurunan keanekaragaman jenis flora, fauna dan mikroba. Munculnya kolong-kolong bekas galian juga mengganggu sistem drainase dan mempersulit dalam pemanfaatan lahan selanjutnya (Lima et al.,2016)

Tanah lapisan atas hasil reklamasi penambangan emas rakyat secara terbuka terjadi penurunan status hara tanah, populasi mikroba dan serangga penyubur tanah, serta merubah iklim mikro menjadi kurang baik untuk organism hidup. Dariah et al. (2010) menyatakan bahwa umumnya perencanaan penutupan tambang (termasuk reklamasinya) tidak terintegrasi dengan operasi pertambangan 
Jurnal Media Pertanian Vol. 3 No. 2 Tahun 2018 Hal. 54 - 60

Media Komunikasi Hasil Penelitian dan Review Literatur Bidang Ilmu Agronomi ISSN print $2503-1279$ ISSN online $2581-1606$

sejak awal sampai penutupan, sehingga pasca penambangan timbul berbagai masalah.

Penggunaan alat berat dalam kegiatan penambangan dapat mengakibatkan pemadatan tanah, sehingga menurunkan porositas, permeabilitas dan kapasitas penahan air tanah. Masalah yang dijumpai dalam mereklamasi lahan bekas tambang adalah masalah fisik, kimia (berupa nutrisi maupun keracuanan hara) dan biologi. Kegiatan pertambangan mempengaruhi solum tanah dan terjadinya pemadatan tanah, mempengaruhi stabilitas tanah dan bentuk lahan. Pada proses akhir penambangan batasan tanah secara alamiah sudah tidak jelas lagi karena dalam proses penimbunan kembali tidak dapat dibedakan hubungan genetis antara bahan induk, overburden dan top soil. Lahan bekas penambangan umumnya mengalami dampak penurunan kesuburan tanah, khususnya kandungan bahan organik tanah (Kodir, 2017).

Hancurnya struktur tanah timbunan juga menurunkan stabilitas tanah, merubah distribusi pori tanah yang berperanan penting dalam memegang air, merusak saluran-saluran pori tanah yang berperanan penting dalam meresapkan air ke dalam tanah, dan meningkatkan potensi terjadinya erosi. Hilangnya/terbenamnya tanah lapisan atas yang subur akan menurunkan daya dukung tanah untuk pertumbuhan tanaman. Hilangnya tanah lapisan atas mengakibatkan sifat fisik (aerasi, permeabilitas dan stabilitas agregat) lebih buruk dan hasil tanaman semusim lebih rendah dibandingkan dengan tanah utuh (Laura et al., 2014).

Kesuburan tanah pada lahan reklamasi tambang batubara muda tergolong sangat rendah. Kandungan unsur hara makro yaitu N, P dan K semuanya bekisar sangat rendah di lapisan atas dan lapisan bawah. Reaksi tanah masam serta kapasitas tukar kation sangat rendah. Umumnya topografi pada areal bekas penambangan yang telah direklamasi berupa berbukit dengan lereng $>8 \%$ kecuali pada areal galian yang ditutup rata-rata datar, berombak dan landau (Purnamayani, 2016).

\section{METODE PENELITIAN}

Pelaksanaan penelitian dilakukan dengan mengambil sampel tanah pada area bekas penambangan, di Desa Tanjung Pauh KM 39 Kecamatan Mestong Kabupaten Muaro Jambi, dan tanah di analisis di Laboratorium Tanah Unsri dan Laboratorium Unbari.

Penelitian menggunakan metode survey di lokasi lahan bekas penambangan dan analisis tanah di Laboratorium. Untuk mendapatkan data maka dilakukan pengambilan sampel pada beberapa lokasi di lahan tambang. Pengambilan sampel tanah dilakukan dengan sengaja (purposive sampling) pada kedalaman $0-30 \mathrm{~cm}$ pada 10 titik individu tanah, lalu dicampur secara komposit dan diambil sebanyak 3 sampel sebagai ulangan. Tanah dari lapangan dikeringanginkan, kemudian dipecah agar lebih halus, lalu diaduk secara merata dan diayak dengan ayakan bermata saring $0,5 \times 0,5 \mathrm{~cm}$. Selanjutnya tanah siap untuk di analisis.

Analisis kimia tanah terdiri dari; P tersedia (Bray-I), Fe (ekstrak dietilene triamine penta acetic acid), $\mathrm{N}$ total (Kjeldahl), K-dd (titrasi NH4Oac.pH 7), Ca- 
Jurnal Media Pertanian Vol. 3 No. 2 Tahun 2018 Hal. 54 - 60

Media Komunikasi Hasil Penelitian dan Review Literatur Bidang Ilmu Agronomi ISSN print $2503-1279$ ISSN online $2581-1606$

dd (titrasi NH4Oac.pH 7), Mg-dd (titrasi NH4Oac.pH 7), Na- dd (titrasi NH4Oac.pH 7), C-organik (Walkley Black) dan KTK (titrasi NH4Oac.pH 7), S (spektofotometri), $\mathrm{pH} \mathrm{H} 2 \mathrm{O}$ (1:1) dan $\mathrm{pH} \mathrm{KCl} \mathrm{(1:1)} \mathrm{metode} \mathrm{elektrometri,} \mathrm{EC} \mathrm{(EC}$ meter), Al-dd ( $\mathrm{N} \mathrm{KCl}$ titrasi), $\mathrm{H}$-dd ( $\mathrm{N} \mathrm{KCl}$ titrasi), kejenuhan $\mathrm{Al}$, Analisis fisik tanah terdiri dari; kadar air tanah (gravimetri), tekstur (Hidrometer), dan kapasitas daya pegang air (Gravimetri).

Analisis data keragaman karakteristik jenis tanah pasca penambangan disajikan dalam bentuk tabel dan dibahas secara deskriptif.

\section{HASIL DAN PEMBAHASAN}

Kondisi wilayah Desa Tanjung Pauh beriklim tropis dengan temperature rata-rata $32^{\circ} \mathrm{C}$, curah hujan berdasarkan $\mathrm{BMKG}$ merata sepanjang tahun 16 hari/bulan dengan rata-rata $186 \mathrm{~mm} /$ hari. Sebelum dilakukan penambangan, vegetasi yang ada di wilayah tambang diantaranya pinang, karet, durian, jengkol, terentang, mersawa, dan medang (Purnamayani, 2016).

Hasil analisis tanah pada sampel tanah di area pasca penambangan, di Desa Tanjung Pauh KM 39 Kecamatan Mestong Kabupaten Muaro Jambi (Tabel 1). Topografi wilayah datar, berombak dan landai. Tekstur tanah liat berdebu dengan tanah yang tidak berstruktur yaitu masif atau pejal. Kondisi kadar air tanah hanya mencapai $20,51 \%$ dengan kondisi kapasitas daya pegang air sebesar 15\% (Tabel 1). Kedaan sifat fisik tanah ini menggambarkan bahwa tanah lahan pasca penambangan memiliki kondisi fisik yang kurang baik dan kurang mendukung untuk pertumbuhan dan perkembangan tanaman. Hal ini sejalan dengan Kailei et al. (2016); Purnamayani (2016); Kodir et al. (2017) bahwa kegiatan pertambangan dapat menurunkan produktivitas tanah, pemadatan tanah, erosi dan sedimentasi, gerakan tanah atau longsor, struktur tanah penutup rusak, tanah lapisan atas bercampur ataupun terbenam di lapisan dalam. Daya dukung tanah lapisan atas pasca penambangan untuk pertumbuhan tanaman menjadi rendah.

Hasil analisis kimia tanah (Tabel 1) menunjukkan tingkat kemasaman tanah berada pada posisi sangat masam $\mathrm{pH} 4$, kejenuhan $\mathrm{Al}$ kriteria tinggi sebesar $52,86 \%$, dan kadar besi $1,51 \%$ kriteria tinggi. Rendahnya nilai $\mathrm{pH}$ tanah dapat disebabkan oleh kadar Al-dd dan kejenuhan Al serta kadar besi yang tinggi sehingga mendorong peningkatan kadar $\mathrm{H}^{+}$di dalam tanah. Yuwono dan Rosmarkam (2008) menjelaskan apabila konsentrasi $\mathrm{H}^{+}$dalam larutan tanah lebih banyak dari $\mathrm{OH}^{-}$maka suasana larutan tanah menjadi asam. $\mathrm{pH}$ tanah sangat menentukan pertumbuhan dan produksi tanaman. PH tanah yang optimal bagi pertumbuhan kebanyakan tanaman makanana ternak adalah antara 5,6-6,0. Pada tanah $\mathrm{pH}$ lebih rendah dari 5,6 pada umumnya pertumbuhan tanaman menjadi terhambat akibat rendahnya ketersediaan unsur hara penting seperti fosfor dan nitrogen. Bila $\mathrm{pH}$ lebih rendah dari 4.0 pada umumnya terjadi kenaikan $\mathrm{Al}^{3+}$ dalam larutan tanah yang berdampak secara fisik merusak sistem perakaran, terutama akar-akar muda, sehingga pertumbuhan tanaman menjadiaa terhambat. Konsentrasi Alumunium dan besi $(\mathrm{Fe})$ yang tinggi pada tanah memungkinkan terjadinya ikatan terhadap fosfor dalam bentuk alumunium fosfat atau Fe-fosfat. $\mathrm{P}$ yang terikat oleh alumunium tidak dapat digunakan oleh tanaman. 
Jurnal Media Pertanian Vol. 3 No. 2 Tahun 2018 Hal. 54 - 60

Media Komunikasi Hasil Penelitian dan Review Literatur Bidang Ilmu Agronomi ISSN print $2503-1279$ ISSN online $2581-1606$

Tabel 1. Hasil analisis Kimia dan Fisik tanah satu tahun pasca penambangan

\begin{tabular}{|c|c|c|c|}
\hline No & Jenis Analisis & Nilai & Kriteria *) \\
\hline 1 & $\mathrm{pH} H 2 \mathrm{O}(1: 1)$ & 4,00 & Sangat Masam \\
\hline 2 & pH KCl (1:1) & 3,30 & \\
\hline 3 & $\mathrm{EC}\left(\mathrm{mS} \mathrm{Cm}^{-1}\right)$ & 0,18 & Bebas Garam \\
\hline 4 & C-organik (\%) & 0,16 & Sangat Rendah \\
\hline 5 & N-total (\%) & 0,11 & Rendah \\
\hline 6 & $\mathrm{C} / \mathrm{N}$ & 1,46 & Sangat Rendah \\
\hline 7 & P Bray I (mg kg $\left.{ }^{-1}\right)$ & 9,20 & Rendah \\
\hline 8 & K-total $\left(\mathrm{mg} \mathrm{kg}^{-1}\right)$ & 0,15 & Rendah \\
\hline 9 & Ca-dd $\left(\mathrm{cmol}(+) \mathrm{kg}^{-1}\right)$ & 6,00 & Sedang \\
\hline 10 & & 1,30 & Sedang \\
\hline 11 & $\begin{array}{l}\text { Mg-da }\left(\mathrm{cmol}(+) \mathrm{Kg}^{-1}\right) \\
\mathrm{Na}-\mathrm{dd}\left(\mathrm{cmol}(+) \mathrm{kg}^{-1}\right)\end{array}$ & 0,12 & Rendah \\
\hline 12 & $\mathrm{Na}-\mathrm{dd}\left(\mathrm{cmol}(+) \mathrm{kg}_{-1}\right)$ & 0,10 & Rendah \\
\hline 13 & $\mathrm{~K}-\mathrm{dd}\left(\mathrm{cmol}(+) \mathrm{kg}^{-1}\right)$ & 15,21 & Rendah \\
\hline 14 & KTK $\left(\mathrm{cmol}(+) \mathrm{kg}^{-1}\right)$ & 8,34 & \\
\hline 15 & Al-dd $\left(\mathrm{cmol}(+) \mathrm{kg}^{-1}\right)$ & 54,83 & Tinggi \\
\hline 16 & Kejenuhan $\mathrm{Al}(\%)$ & 49,44 & Sedang \\
\hline 17 & Kejenuhan Basa (\%) & 1,51 & Tinggi \\
\hline 18 & $\mathrm{Fe}(\%)$ & 0,14 & Rendah \\
\hline 19 & $\mathrm{~S}(\%)$ & 20,51 & \\
\hline 20 & Kadar Air Tanah (\%) & 14,90 & \\
\hline \multirow[t]{3}{*}{21} & Fraksi Pasir (\%) & 45,00 & \\
\hline & Debu $(\%)$ & 40,10 & \\
\hline & Liat (\%) & Liat Berdebu & \\
\hline 22 & Tekstur & $15 \%$ & \\
\hline
\end{tabular}

Dari hasil penelitian KTK (Kapasitas Tukar Kation) tanah sebesar 15,21 cmol(+) $\mathrm{kg}^{-1}$ tergolong rendah. Hal ini disebabkan adanya partikel penyusun tanah didominasi oleh fraksi debu yang memiliki luas permukaan koloid yang kecil, sehingga KTK tanah rendah. Selain itu juga disebabkan karena tanah mempunyai $\mathrm{pH}$ yang rendah sehingga berpengaruh terhadap KTK tanah. Yuwono dan Rosmarkam (2008) menjelaskan bahwa besarnya KTK tanah dipengaruhi oleh sifat dan ciri tanah tersebut yaitu : $\mathrm{pH}$ tanah, tekstur atau jumlah liat, dan jenis mineral liat, dan bahan organik.

Kejenuhan basa (KB) sebesar 49,44\% tergolong sedang. Keadaan ini menunjukkan permukaan koloid (kompleks pertukaran) tanah tersebut didominasi oleh kation asam terutama $\mathrm{Al}$, sehingga menyebabkan kejenuhan $\mathrm{Al}$ tergolong sangat tinggi. Seperti dikemukakan oleh Winarso (2005) bahwa kejenuhan basa menggambarkan proporsi nisbi basa dapat dipertukarkan pada koloid tanah. Pada tanah di daerah yang telah mengalami pelapukan lanjut, sebagian besar dari komplek pertukaran pada permukaan koloid diduduki oleh kation Al. Persen KB merupakan perbandingan antara jumlah miliekuivalen kation basa dengan miliekuivalen KTK, bila KB tanah tergolong rendah, maka kation Al merupakan kation yang dominan terjerap pada permukaan koloid. 
Jurnal Media Pertanian Vol. 3 No. 2 Tahun 2018 Hal. 54 - 60

Media Komunikasi Hasil Penelitian dan Review Literatur Bidang Ilmu Agronomi ISSN print $2503-1279$ ISSN online $2581-1606$

Kandungan C-organik pada tanah pasca tambang hasil penelitian tergolong sangat rendah yaitu sebesar $0,16 \%$, kondisi ini menunjukkan bahwa kandungan bahan organik tanah juga sangat rendah. Nilai $\mathrm{C} / \mathrm{N}$ tanah 1,46 tergolong sangat rendah menggambarkan bahwa energi untuk mikroorganisme tanah dalam proses perombakan sangat rendah, sehinggga ketersediaan unsur hara juga menjadi lebih rendah.

Hasil analisis tanah memperlihatkan bahwa $\mathrm{N}$ total $0,11 \%$, $\mathrm{P}$ tersedia 9,20 $\mathrm{mg} \mathrm{kg}^{-1}$ dan $\mathrm{K}$ total tanah $0,15 \mathrm{mg} \mathrm{kg}^{-1}$ masing-masing tergolong rendah. Kondisi ini menunjukkan bahwa ketersedian unsur hara $\mathrm{N} P$ dan $\mathrm{K}$ pada tanah sangat terbatas dan sangat tidak mendukung untuk mendukung pertumbuhan dan perkembangan tanaman. Keadaan ini dapat disebabkan tanah tersebut terbentuk dari bahan induk (batuan/mineral) yang miskin unsur $\mathrm{P}$ dan kandungan $\mathrm{P}$ dalam bahan organik juga rendah, seperti dinyatakan oleh Munawar (2013) bahwa P dalam tanah berasal dari desintegrasi mineral yang mengandung $\mathrm{P}$ seperti apatit, dan dekomposisi bahan organik. Kelarutan senyawa $\mathrm{P}$ anorganik dan $\mathrm{P}$ organik di dalam tanah umumnya sangat rendah, sehingga hanya sebagian kecil $\mathrm{P}$ tanah yang berada dalam larutan tanah (P tersedia). Di samping itu juga dapat disebabkan $\mathrm{pH}$ tanah yang rendah sehingga kelarutan Al yang tinggi menyebabkan $\mathrm{P}$ menjadi tidak tersedia. Pada tanah masam ( $\mathrm{pH}$ rendah), $\mathrm{P}$ larut akan bereaksi dengan $\mathrm{Al}$ dan Fe dan oksida-oksida hidrus lainnya membentuk senyawa Al-P dan FeP yang relatif kurang larut, sehingga $P$ tidak dapat diserap oleh tanaman. Selanjutnya Greb (1985) dalam Subowo (2002) menjelaskan bahwa kehilangan tanah lapisan atas beberapa sentimeter dapat menurunkan produktivitas sebesar $40 \%$ pada tanah subur, dan 60\% pada tanah tidak subur. Tanah lapisan atas lahan bekas penambangan terbuka memiliki kandungan $\mathrm{N}$ dan $\mathrm{P}$ rendah, dan populasi mikroba tanah rendah dibandingkan dengan tanah hutan di sekitarnya.

\section{KESIMPULAN}

Karakteristik kimia dan fisik tanah pasca tambang di lokasi penelitian Desa Tanjung Pauh : tingkat kemasaman tanah berada pada posisi sangat masam pH 4, kejenuhan Al kriteria tinggi sebesar 52,86\%, kadar besi 1,51\% kriteria tinggi, KTK (Kapasitas Tukar Kation) tanah sebesar 15,21 cmol(+) $\mathrm{kg}^{-1}$ tergolong rendah, Kejenuhan Basa (KB) sebesar 49,44\% tergolong sedang, C-organik sangat rendah yaitu sebesar $0,16 \%$, Nilai $\mathrm{C} / \mathrm{N}$ tanah 1,46 tergolong sangat rendah, $\mathrm{N}$ total $0,11 \%$, $\mathrm{P}$ tersedia $9,20 \mathrm{mg} \mathrm{kg}^{-1}$ dan $\mathrm{K}$ total tanah $0,15 \mathrm{mg} \mathrm{kg}^{-1}$ masingmasing tergolong rendah.

Tanah pasca penambangan memiliki karakteristik fisik dan kimia tanah yang kurang baik sebagai media tanam. Apabila akan dimanfatkan sebagai media tanam maka harus disertai dengan input teknologi yang tepat. 
Jurnal Media Pertanian Vol. 3 No. 2 Tahun 2018 Hal. 54 - 60

Media Komunikasi Hasil Penelitian dan Review Literatur Bidang Ilmu Agronomi

\section{DAFTAR PUSTAKA}

Dariah.A , Abdurachman.A, dan Subardja. D. 2010. Reklamasi Lahan Bekas Penambangan Untuk Perluasan Areal Pertanian. Jurnal Sumberdaya Lahan .4(1):1-12.

Kailei, Pan. H, and Lin. C. 2016. A landscape approach towards ecological restoration and sustainable development of mining areas. Ecological Engineering. 90:320-325. https://doi.org/10.1016/j.ecoleng.2016.01.080Get rights and content.

Kodir.H, Hartono.D.M, Haeruman.H, and Mansur.I. 2017. Integreted post mining landscape for sustanable land use:A case study in South Sumatera, Indonesia. Sustainable Environment Research. 27 : 203-213.

Lima. A.T, Mitchell. K, David. W, Connell. O, Verhoeven. J, and Cappellen. P.V. 2016. The legacy of surface mining: Remediation, restoration, reclamation and rehabilitation. Environmental Science and Policy. 66:227233. https://doi.org/10.1016/j.envsci.2016.07.011.

Laura J, Chris. S, Moran. J, Barrett. D.J, Soares. B.S, Filho. 2014. Processes of land use change in mining regions. Journal of Cleaner Production. 84:494501.https://doi.org/10.1016/j.jclepro.2014.03.084Get rights and content.

Munawar, A. 2013. Kesuburan Tanah dan Nutrisi Tanaman. IPB Press, Bogor

Purnamayani.R. 2016. Karakteristik kimia tanah lahan reklamasi tambang batubara di Provinsi Jambi. Prosiding Seminar Nasional Lahan Suboptimal. 20-21 Oktober 2016.Palembang.

Shukla. S.K, Mishra. R.K, Pandey. M, Mishra. V, Pathak. A, Pandey. A, Kumar. $\mathrm{R}$, and Dikshit. A. 2016. Land Reformation Using Plant GrowthPromoting Rhizobacteria in the Context of Heavy Metal Contamination. Pp.499-529. Plant Metal Interaction. https://doi.org/10.1016/B978-0-12803158-2.00021-7 Get rights and content.

Subowo. G. 2002. Pemanfaatan Cacing Tanah (Pheretima hupiensis) untuk Meningkatkan Produktivitas Ultisol Lahan Kering. Disertasi Program Pasca Sarjana IPB.

Subardja, D. 2009. Karakteristik dan Potensi Lahan Bekas Tambang Timah di Bangka Belitung untuk Pertanian. Buku I, Semilokanas Inovasi Sumberdaya Lahan, p 189-197.

Wardoyo,S.S. 2007. Revegetasi sebagai alternative memperbaiki sifat kimia tanah pada lahan bekas tambang batubara.Proseding Seminar dan Kongres HITI IX Yogyakarta. 2-7 Desember 2007.

Winarso. S. 2005. Kesuburan Tanah Dasar Kesehatan dan Kualitas Tanah. Edisi 1. Yogyakarta. Penerbit Gaya Media. Pp $239-263$

Yuwono. NW dan Rosmarkam. A. 2008. Ilmu Kesuburan Tanah. Edisi 4. Yogyakarta. Penerbit Kanisus. pp $23-32$. 